\title{
Contents
}

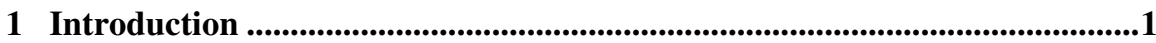
Àngels Massip-Bonet, Albert Bastardas-Boada

2 Facing Complexity: Prediction vs. Adaptation .....................................................3

Carlos Gershenson

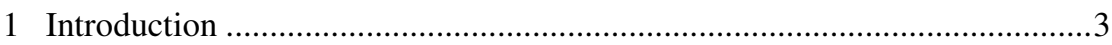

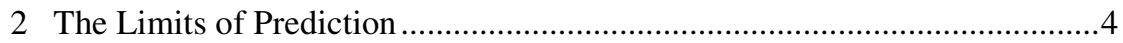

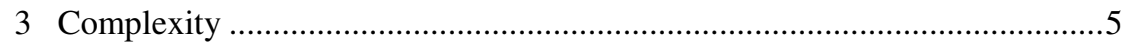

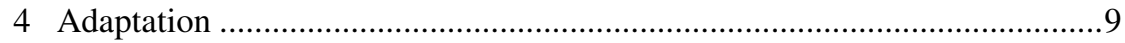

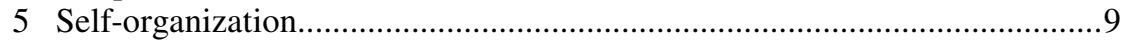

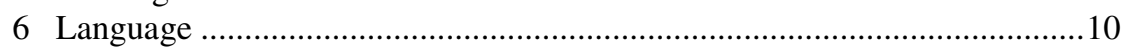

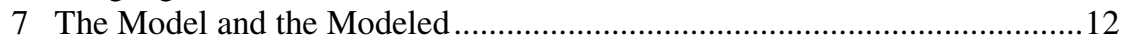

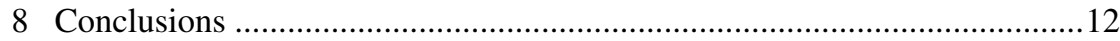

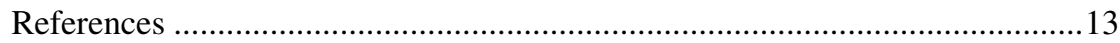

3 Sociolinguistics: Towards a Complex Ecological View....................................15 Albert Bastardas-Boada

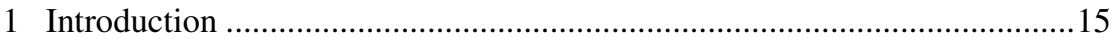

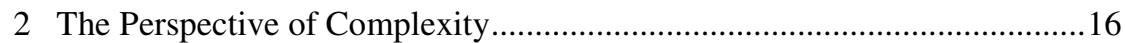

3 The Main Aspects of an Ecological Complexity: A Proposal .......................18

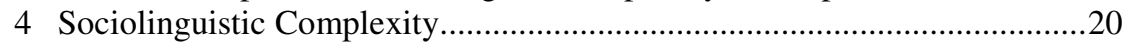

5 The (Bio)ecological Perspective as a Metaphor ………………………......23

6 Towards a Socio-emo-cognitive Language Ecology ………........................28

7 Time and Co-evolution in Sociolinguistics...................................................32

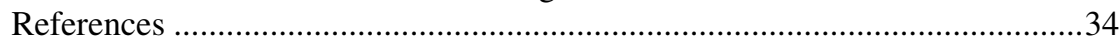

4 Language as a Complex Adaptive System: Towards an Integrative Linguistics.....................................................................................................................35 Àngels Massip-Bonet

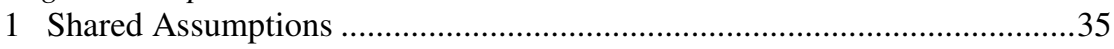

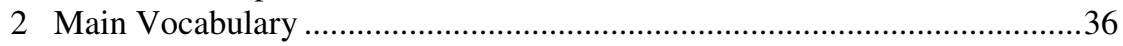

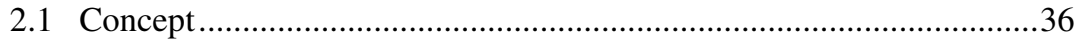

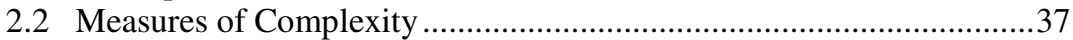

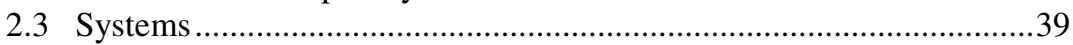

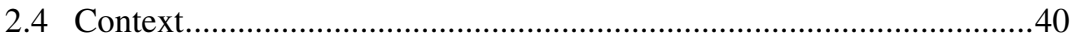

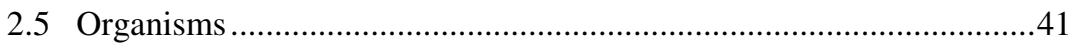


3 Change in Complex Systems ........................................................4

3.1 Irreversibility, Self-organization and Emergence ..............................41

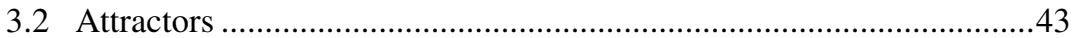

3.3 On the Edge of Chaos ...................................................................44

3.4 Co-adaptation.........................................................................44

4 Characteristics of the Language System as a CAS

(Complex Adaptive System) ...................................................................44

4.1 Distributed Control and Collective Emergence .................................45

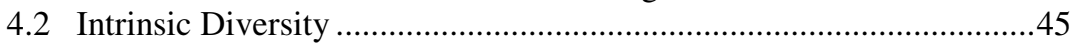

4.3 Perpetual Dynamics ....................................................................45

4.4 Adaptation through Factors of Amplification and Competition ..........46

4.5 Non-linearity and Phase Transitions ..............................................46

4.6 Sensitive Dependence on Network Structure.......................................46

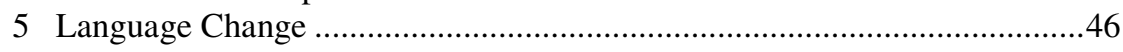

5.1 Complexity and Change..............................................................46

5.2 Language Change and Variation.......................................................47

5.3 Parallels between Biological and Language Systems ........................48

6 Language Evolution and Language Change ................................................48

7 Language and Thought: Grammar ...................................................49

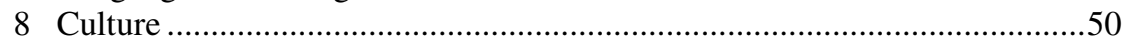

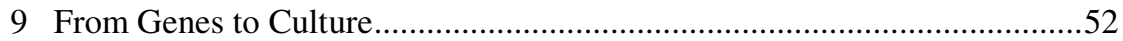

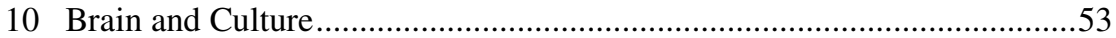

11 Theories and Time ..............................................................................53

11.1 Linguistic Theories and Complexity .............................................53

11.2 Reducing Complexity .................................................................54

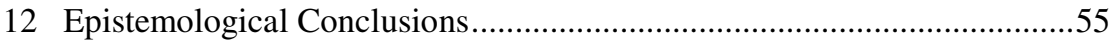

12.1 Brain Activity and Epistemology ...............................................55

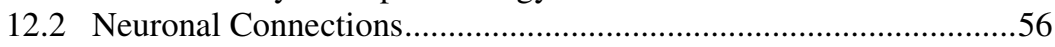

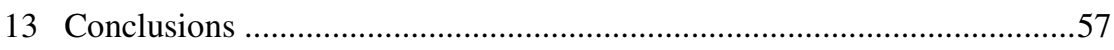

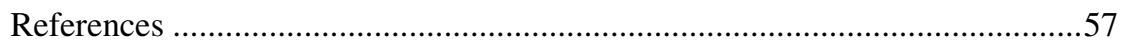

5 An Experientially-Based Informationless Communication ..........................61

Òscar Vilarroya

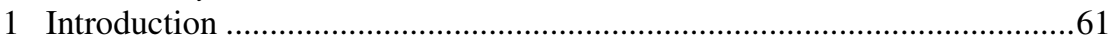

2 An Experientially-Based Communication .............................................64

3 Information in Experientially-Based Communication ................................. 70

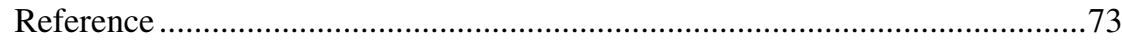

6 Conversation as Emergent Function .....................................................................75

Xavier Martorell

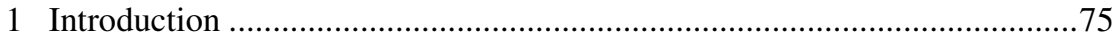

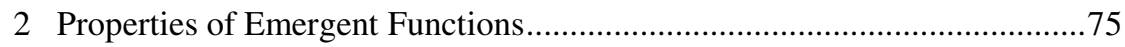

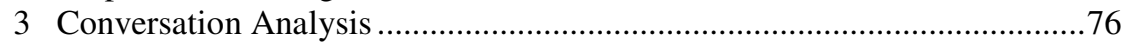

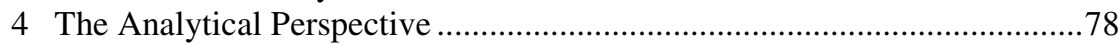

5 The Complex Perspective ........................................................................79

5.1 Mind-Reading Modules ....................................................................79 


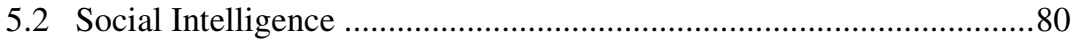

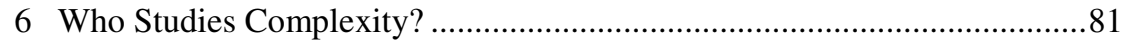

7 How Are Cognitive Functions Generated? ..................................................

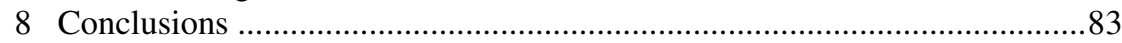

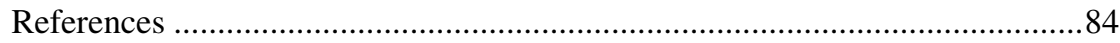

7 Communication Situations: A Dialogic Quiz?......................................................85

Enric Puig-Giralt

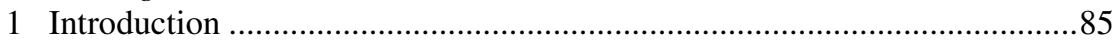

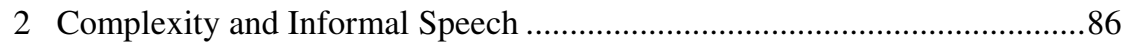

3 From the Historical Discourse to the Art of Advertising ..............................87

4 A Whole Music Experience ......................................................................91

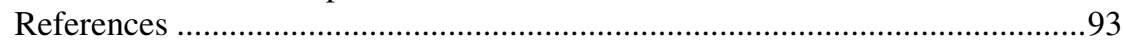

8 Education, Emotion, Complexity ………………………………….......................95

Pere Darder

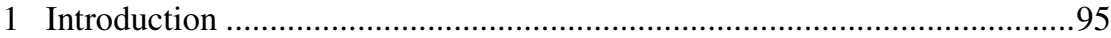

2 References to the Theory of Complexity …………………........................96

3 The Emotions, Here and Now.................................................................96

4 The Characterization of Emotions …………………..................................97

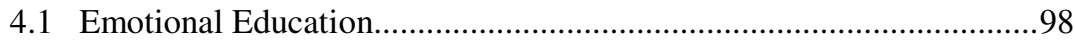

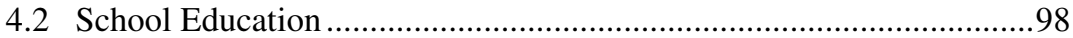

4.3 The Emotional Competence of the Teacher...........................................99

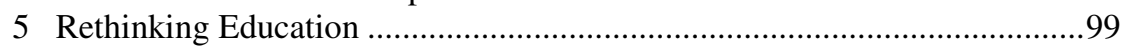

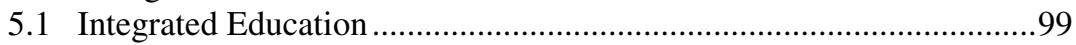

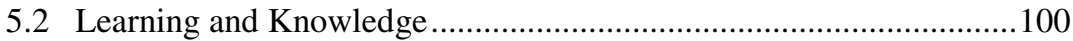

5.3 Participation and Governance in Education ........................................100

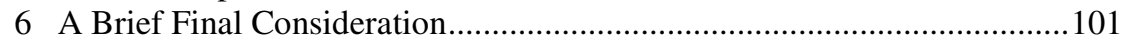

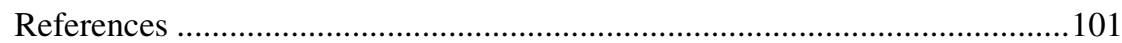

9 Minds and Screens: Communication and Socialization from a Complexity Perspective ..............................................................................................103

Magdalena Albero-Andrés

1 Assumptions about the Relationship between Media and Young

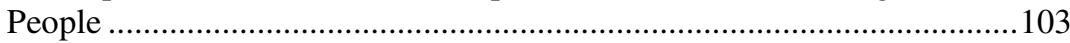

2 Causes of the Use of the Non-complex Approach ......................................106

3 How a Non-complex Approach Misleads Us ..............................................107

4 Applying a Complexity Perspective to the Use of Media Products and Media Education in Schools ..................................................................110

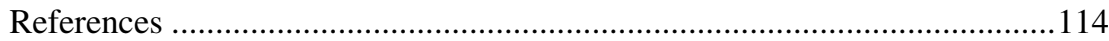

10 Self-organization in Communicating Groups: The Emergence of Coordination, Shared References and Collective Intelligence ..................117 Francis Heylighen

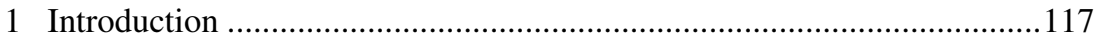

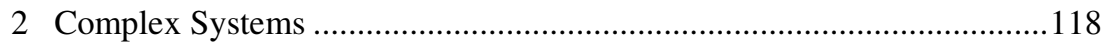


3 Self-organization................................................................... 120

4 Self-organization as a Problem of Coordination................................... 122

4.1 Self-organization of Alignment ................................................123

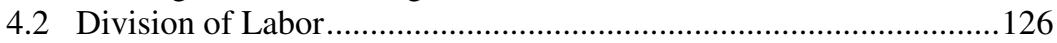

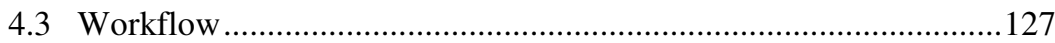

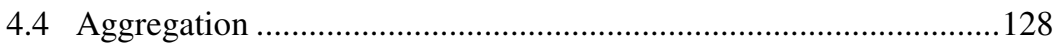

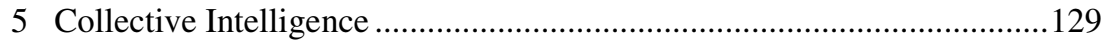

5.1 Requirements for Collective Intelligence .................................... 129

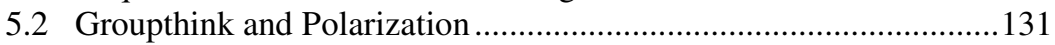

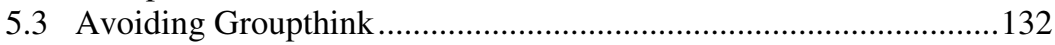

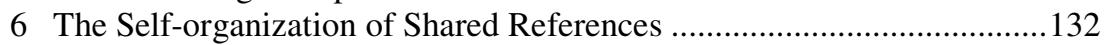

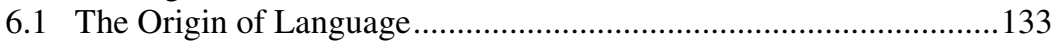

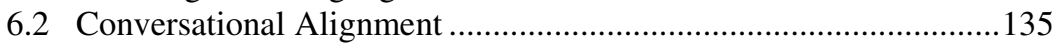

6.3 Group Alignment ....................................................................... 136

7 An Experiment in Collective Intelligence......................................... 137

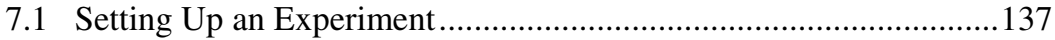

7.2 Results of the Experiment ...................................................................141

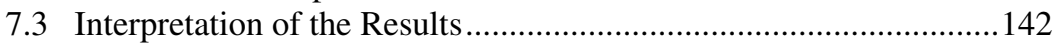

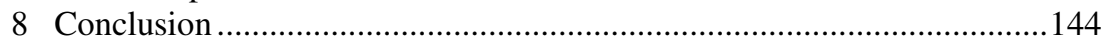

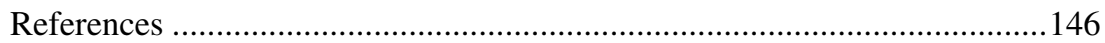

11 General Linguistics and Communication Sciences: Sociocomplexity as an Integrative Perspective ..............................................................151

Albert Bastardas-Boada

1 Introduction: The Need for a Perspective of Complexity ......................151

2 Towards a Paradigm of Complexity .......................................................153

2.1 Constructing a World. The Representation of Reality, and

Scientific Activity ........................................................................ 153

2.2 (Re)thinking Reality ............................................................. 154

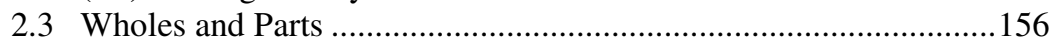

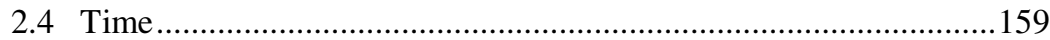

2.5 Human Beings: The Centrality of the Mind/Brain..........................161

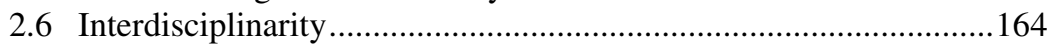

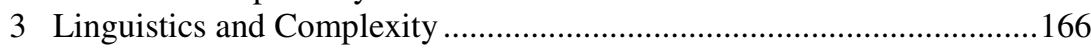

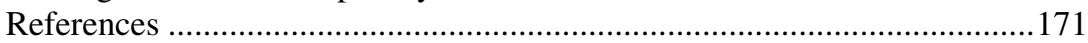

12 The Fuzzy Complexity of Language...................................................175

\section{Frederic Munné}

1 Fuzziness as a Property of Complex Systems.....................................175

2 Inverting the Laws of Aristotelian Logic ............................................177

3 Language as a Fuzzy System ................................................................178

4 Delimitation: Reducing the Fuzziness .................................................180

5 Categorization: A Resource for Definition ........................................182

6 Dichotomization: Glossing over the Fuzziness....................................... 184

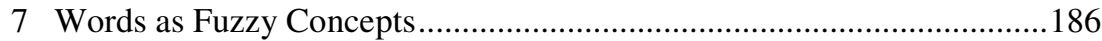

8 Words and Definitions ........................................................................ 189 


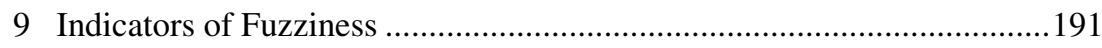

10 Expanding Fuzziness: Hypertext ...................................................193

11 Returning to Where We Began ......................................................... 195

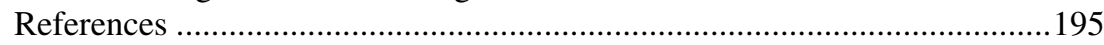

13 The Emergence of Complexity in Language: An Evolutionary

Perspective...............................................................................................................197

Salikoko S. Mufwene

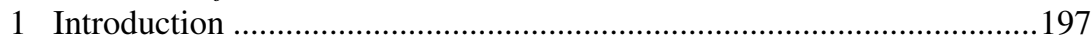

2 Languages as Technologies ................................................................201

3 The Phylogenetic Emergence of Complexity ..........................................204

3.1 The Nature of Linguistic Complexity .............................................204

3.2 How Did Complexity Emerge Phylogenetically in Language? ......208

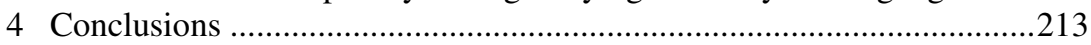

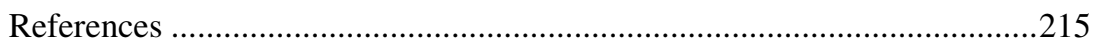

14 The Ecology of Pressures: Towards a Tool to Analyze the Complex Process of Language Shift and Maintenance...........................................219

Roland Terborg and Laura García-Landa

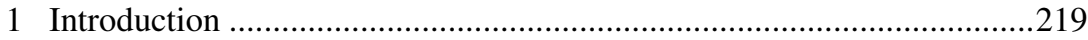

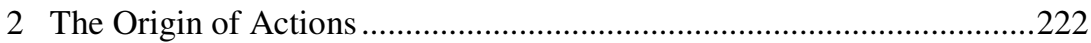

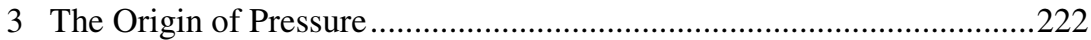

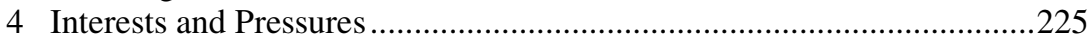

5 The State of the World and Pressures ........................................................228

6 Competence and Common Routine ………………….............................229

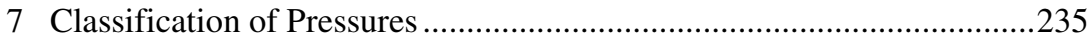

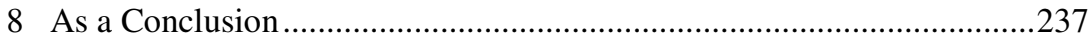

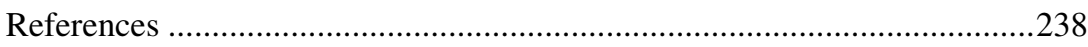

15 Ethics and Progress in Today's World ...........................................................241

Federico Mayor Zaragoza

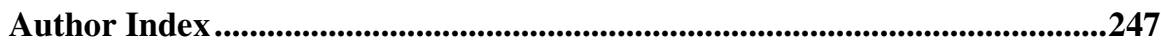

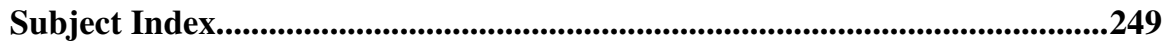

